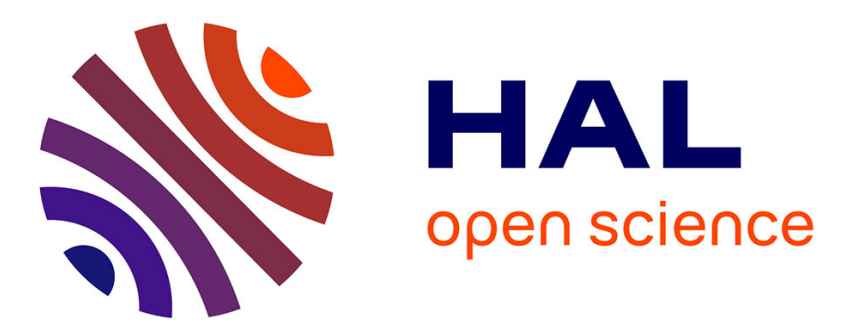

\title{
Environmental-energy analysis and the importance of design and remanufacturing recycled materials
}

\author{
Francisco Jimenez, Stephane Pompidou, Nicolas Perry
}

\section{To cite this version:}

Francisco Jimenez, Stephane Pompidou, Nicolas Perry. Environmental-energy analysis and the importance of design and remanufacturing recycled materials. International Journal on Interactive Design and Manufacturing, 2016, 10 (3), pp.241-249. 10.1007/s12008-016-0321-8 . hal-01619819

\section{HAL Id: hal-01619819 \\ https://hal.science/hal-01619819}

Submitted on 19 Oct 2017

HAL is a multi-disciplinary open access archive for the deposit and dissemination of scientific research documents, whether they are published or not. The documents may come from teaching and research institutions in France or abroad, or from public or private research centers.
L'archive ouverte pluridisciplinaire HAL, est destinée au dépôt et à la diffusion de documents scientifiques de niveau recherche, publiés ou non, émanant des établissements d'enseignement et de recherche français ou étrangers, des laboratoires publics ou privés. 


\title{
ENVIRONMENTAL-ENERGY ANALYSIS AND THE IMPORTANCE OF DESIGN AND REMANUFACTURING RECYCLED MATERIALS
}

\author{
Francisco Jimenez ${ }^{1}$, Stephane Pompidou ${ }^{2}$, Nicolas Perry ${ }^{3}(\tilde{\mathrm{I}})$ \\ ${ }^{1}$ CIATEQ, Mexico City, Mexico \\ ${ }^{2}$ I2M - UMR 5295 - U.Bordeaux1 - IUT, F-33175 Gradignan, France \\ ${ }^{3}$ I2M - UMR 5295 - Arts et Métiers ParisTech, F-33400 Talence, France
}

\begin{abstract}
This paper proposes a framework that interrelates the life cycle of the product, remanufacturing and recycling for plastics. The paper analyses the different chemical processes of recycling polymer wastes. We introduce a thermodynamic calculation of the energy consumed and $\mathrm{CO} 2$ emissions for all types of waste (municipal, electronic, vehicle). The remanufacturing process could reduce the amount of CO2 emissions through feedback to the product design stage with robust platforms that extend the product life cycle. In order to meet the requirements of remanufacturing we combine mechanical and chemical recycling solutions. These recycling processes must undergo a thermodynamic analysis to optimize energy and decrease the minimum $\mathrm{CO} 2$ emissions, i.e. recycling processes in line with the ultimate objective, which is the reduction of $\mathrm{CO} 2$ emissions and slowing a part of the problem global warming.
\end{abstract}

\section{KEYWORDS}

Recycling, polymer, thermodynamic, $\mathrm{CO} 2$ emissions

\section{Introduction}

Today designers have to take into account indicators related to environmental impacts of the products during their whole life cycle. From the cradle (raw material extraction) to grave (end of life of the product), all the impacts of the life phases of the product are evaluated. These impacts and emissions evaluations (such as $\mathrm{CO} 2$, energy or water consumption, etc) help designers to select and develop eco-designed products. End of life (EoL) of the products becomes a major question due to the needs of material efficiency (meaning saving and recycling a lot of materials when the product is at its end of life). Closing the material loop and circular economy perspectives are the today solutions for the product and its related organization development.

In order to improve the design for End of Life, recycling solutions has to be evaluated and 
sometime to be developed. The integration, within the designer environment, of this topic needs to have a set of EoL's solutions figures. This analysis gives also the opportunity to improve these solution and eco-design their processes. One option relies on integrating renewable energy into the recycling technology development. This is the goal of this paper. Data bases of recycling processes or recycling functional unit descriptions could give opportunities to have early evaluations for the EoL impacts, into the product development process. Other EoL alternatives, such as re-use or remanufacturing of components, are not taken into consideration into this paper, even if these solutions have a very positive impact on the environmental profile of the products at their EoL.

The current process used for the processing and industrial recycling of polymers to manufacture packaging, packaging and engineering plastics in the automotive and electronics industry uses fossil fuel energy. The fossil fuels used in burning, biomass burning, cement manufacturing, and changes in land use (mainly deforestation) are generating $\mathrm{CO} 2$ gases. These gases are trapping an increasing proportion of terrestrial infrared radiation and the global temperature is expected to increase 0.3 to $0.4^{\circ} \mathrm{C}$ per decade (so-called greenhouse effect and global warming) [1-7]. Consequently, improvements should be made in plastic product design and manufacturing (integrating recycled materials and actions taken to reduce manufacturing impacts). The end of life has to be improved (in terms of efficiency of recycling but also collection and use) and must also be analyzed from the $\mathrm{CO} 2$ and energy consumption perspective.

This paper presents a unified scheme of the product life cycle and interaction with recycling and remanufacturing. Remanufacturing (or even better re-use) is an important process for reducing $\mathrm{CO} 2$ emissions. This work emphasizes the need to design life cycle products that can be prolonged by remanufacturing the product. The paper also analyzes the existing processes for recycling plastics by an energy-ecological approach in order to optimize these processes and reduce $\mathrm{CO} 2$ emissions dramatically.

\section{Life cycle, remanufacturing and recycling interaction}

The life cycle of materials is a function of design and technological progress in the market. Unfortunately, in recent decades the design approach has tended to be one of short durability in order to maintain consumption and production flows. The volume of waste has increased tremendously and is now a major global problem. Many countries have cultural levels of consciousness for environmental awareness and litter. However, when all garbage, both organic and inorganic, is discarded in a single container, it creates pockets of infection and logistical problems in collection, transportation and separation of these wastes. This means increased consumption of energy and therefore more $\mathrm{CO} 2$ emissions compared to countries with a culture based on awareness of the environment. The consumer becomes the first link in the recycling chain, separating the different types of waste (paper and cardboard, glass, metals, plastics, food, green waste). This single action on the part of the consumer saves millions of tons of energy and reduces $\mathrm{CO} 2$ emissions considerably because there is specialized transportation taking each type of waste (glass, metal, papers, plastic) directly to appropriate recycling centers. Otherwise, when garbage is not separated, it goes to a collection centre, where separation is carried out by industrial machinery which uses a large amount of energy (mainly electricity), water and surfactants to prewash and separate. Total energy consumption and $\mathrm{CO} 2$ emissions increase, as well as the need to install a water treatment plant for sludge generated due to organic waste.

The valorization of plastic consists of burning, with some organic materials, in order to generate power used in heating the cement industry or to produce 
steam to generate electricity. Again, this means a great generation of $\mathrm{CO} 2$ emissions, not to mention other polluting gases. Circular economy and cradle to cradle approaches need interaction between the product life cycle and end of life processes, with and without environmental culture. Recycling, remanufacturing or refurnishing are today's alternatives that have come up again with the need to extend the life of products or materials in order to curb the environmental impact. It implies thinking back for durable product design and being aware that in the culture of consumerism the media product life cycle is very short (disposable) and impacts on global warming.

\section{Pre-recycling steps}

In an environmental culture, plastic can be recycled mechanically or chemically (Fig. 1). Transformation depends on the quality of recycled plastic required, and this also depends on the requirements for integrating the remanufacturing of a product in use or a new product based on design requirements.

The pre-recycling steps require energy and the use of volatile solvents, but are crucial to separating and cleaning the appropriate particle size to be used in the chemical recycling or mechanical process. Based on recent studies, it is estimated that when recycling plastic by separating the mixture of PET and HDPE plastics that have very different densities using an infra-red detector (NIR) and manual separation, then applying a series of treatments (pre-washing, separation by $\mathrm{X}$-ray and metal detectors, grinding, filtration, washing, flotation, drying and sieving to finally get fine granules or flakes of recycled polymers), the power consumption of all these operations is $6828 \mathrm{MJ} /$ ton, compared with using virgin plastic which consumes 72,573 MJ / ton, thus energy saving is $91.4 \%$, and the savings impact on the environment is $1.12 \mathrm{t} \mathrm{CO} 2$ per tonne of plastic recycling [8].

\begin{tabular}{|c|c|c|c|c|c|}
\hline Process & Sub-process & Method & Sub-method & Separated & Reference \\
\hline \multirow{9}{*}{$\begin{array}{l}\text { Mechanical } \\
\text { methods }\end{array}$} & Wet shaking table & Vibration & & PET, PVC-PS & {$[9,10,34]$} \\
\hline & Gravity & Liquid & & PVC-PVDC, PS-PET & {$[12,23,33]$} \\
\hline & \multirow{7}{*}{ Density } & Liquid & Water & HDPE-PP, PET-PVC-PS-ABS & {$[13,14,35]$} \\
\hline & & Liquid & $50 \%$ wt ethanol & PP, HDPE & [13] \\
\hline & & Liquid & Water $-30 \%$ wt $\mathrm{CaCl}_{2}$ & PS-ABS, PET-PVC & {$[13,15,20]$} \\
\hline & & & $\begin{array}{l}\text { Wetting through } \\
\text { adsorption }\end{array}$ & HDPE, PET, PVC, PMMA & [37] \\
\hline & & & Aluminium sulfate & PET, POM, PVC & [36] \\
\hline & & & $\begin{array}{l}\text { Liquid-vapour surface } \\
\text { tension control }\end{array}$ & ABS, PC, PET, HDPE & {$[16,13,25]$} \\
\hline & & & Calcium lignosulfonate & ABS, PET, POM, PVC & {$[17,21]$} \\
\hline $\begin{array}{l}\text { Mineral } \\
\text { processing }\end{array}$ & $\begin{array}{l}\text { Electromagnetic } \\
\text { feeder }\end{array}$ & $\begin{array}{l}\text { Hot water, Vibrating } \\
\text { screen, Bank of flotation } \\
\text { cell }\end{array}$ & $\begin{array}{l}\mathrm{NaOH} \text {-Detergent, } \\
\text { CaLignosulfo-Hostaphat }\end{array}$ & PET, PVC & {$[26]$} \\
\hline $\begin{array}{l}\text { Fluidized bed } \\
\text { technology }\end{array}$ & Vertical column & Water fluid pipeline & & TPU, PVC, PBT, PET & {$[19,30]$} \\
\hline \multirow{3}{*}{ Electric method } & Roll-type corona & Electrostatic separator & $\begin{array}{l}\text { Waste printed circuit } \\
\text { board (PCB) }\end{array}$ & No conductor plastics & {$[11,18]$} \\
\hline & Magnetic field & $\begin{array}{l}\text { Discharging current of a } \\
\text { capacitor }\end{array}$ & $\begin{array}{l}\text { Separating metallic } \\
\text { particles from } \\
\text { metal-plastic mixtures }\end{array}$ & $\begin{array}{l}\text { Plastic mixtures, metallic } \\
\text { particles }\end{array}$ & {$[27,31]$} \\
\hline & Plasma & Oxygen radicals & $\begin{array}{l}\text { Input power of } 250 \mathrm{~W} \text { to } \\
400 \mathrm{~W} \text {, a pulse frequency } \\
\text { of } 2 \mathrm{kHz} \text { to } 12 \mathrm{kHz} \text {, }\end{array}$ & $\begin{array}{l}\text { Carbon fiber composites, PS. } \\
\text { PP }\end{array}$ & {$[26]$} \\
\hline \multirow{2}{*}{$\begin{array}{l}\text { Chemical } \\
\text { methods }\end{array}$} & Ozonation & & & PVC & {$[23,24]$} \\
\hline & Methyl cellulose (MC) & $\begin{array}{l}\text { Chemical factors, and } \\
\text { Gravity factors }\end{array}$ & & $\begin{array}{l}\mathrm{ABS} \text { and } \mathrm{PS}, \mathrm{PET}, \mathrm{PMMA} \text { and } \\
\mathrm{PC}, \mathrm{POM} \text { and } \mathrm{PVC}\end{array}$ & [22] \\
\hline
\end{tabular}


Table 1. Summary of Separation Processes

Separation: To recycle plastics with very similar densities, the separation processes are not simple. These plastics are found in ELV (End-of-Life of Vehicles) and WEEE (Waste Electrical and Electronic Equipment). Many articles have been published on methods of separating plastics of similar density from the most classic, such as floating plastic with water, to remove waste from MSW (Municipal Solid Waste), as well as those listed in Table 1.

Detecting and sorting: different techniques exist: Electromagnetic methods (Near infrared NIR, High resolution imaging X-rays [only separation of PVC from PET] [38], Fluorescent tracer in Ultra violet spectroscopy [inadequacy in the conveyor system at high speeds] [39, 40,41], the magnetic tracer system [quantities of the order of the percent could engender homogenisation problems and affect the mechanical properties of the polymer] [42, 43], XRF (X-ray fluorescence) spectrometry detection of rare earth oxides, used as tracers, blue light absorption [of dark automotive plastic parts] [39, 41], Waste pharmaceutical blister packages; cryo- or electrostatic separation, and combinedprocesses [44, 45].

Most existing methods have an actual separation rate of 80 to $90 \%$, thus affecting the appearance quality of the final product or finished plastic that has been necessary after separation through another process called chemical recycling.

Chemical recycling. The solubility of plastic has made it possible to develop chemical methods to purify and improve their quality through polar and non-polar solvents (xylene, hexane) and achieve their reprecipitation. Structural modification of the polymer chains by gamma irradiation attack or electron irradiation improves the mechanical properties of plastics making them equal to or superior to virgin resin [61-65]. Supercritical fluids (water, ethylene glycol, alcohols) are also a solution for thermoset solvents (using $200-400^{\circ} \mathrm{C}$ temperature range and pressures from 20 to 30
$\mathrm{MPa})$. By polymerizing the monomers again, we obtain a high purity polymer like a virgin polymer. Most researchers focus their efforts on achieving an efficient method to produce polymers of good quality, but the investment aspect of energy and environmental issues (CO2 emissions) are mentioned only briefly. Figure 1 shows some of the main techniques for chemical recycling.

Mechanical recycling. The processes widely used industrially for thermoplastics such as extrusion and injection molding consider that the humidity control of the polymer and the compatibility between them achieve an acceptable plastic product. The purity of recycled plastics derived from mechanical recycling is not appropriate as it does not give an acceptable appearance or texture similar to a product with virgin polymers. This is largely due to the incompatibility between plastics that causes problems in the rheology of extrusion or injection. At polymer-polymer interfaces, the resulting mechanical property is lower than those required by the designer. Some processing techniques for thermosetting plastics are shown in Figure 1, in which the monomers obtained from chemical recycling are used for fibers with plates. Mecanic apply techniques such as Solid State Shear Pulverization [66-76]. It remains incompatibility due to dust at nanometric levels. This technique needs to be further developed for quaternary and quinary systems of incompatible plastics. This would eliminate some stages of pre-recycling, especially filtration and flotation.

Culture of recycling or remanufacturing. Waste management is a contributor to global warming through $\mathrm{CO} 2$ generation. Indeed, many countries are still burning these dusts as valorization (Municipal Solid Waste (MSW), Waste Electrical and Electronic Equipment (WEEE) and recycling of End-of-Life Vehicles (ELV)).

An effective way of reducing these emissions is to prolong product shelf life through a more robust design; this is one goal of eco-design. Another way 
is to develop re-use or remanufacturing solutions to spare parts and adapt them in new products. This means designing products that can be updated independently of technical technology and depending on their history and causes of failure (fatigue, wear, corrosion, creep). It creates a cycle of continuous product improvement and an increase in the cycle product life. A last possibility for the reduction of $\mathrm{CO} 2$ is the development of better end of life valorization, such as recycling possibilities for polymer products.

Some countries have already structured their waste pipelines, pushed by the WEEE or ELV regulations or due to a high national level of sustainable requirements. Some others have no specific structures (collecting or recycling) and have to develop and promote all the alternatives for industrial and collective scales.

\section{Global Analysis of energy consumption and $\mathrm{CO} 2$ emissions by anthropogenic activity}

The main sources of $\mathrm{CO} 2$ emissions from anthropogenic activities considered in this work are those from packaging and packaging intended for the commercial consumption sector, the manufacture of electrical, electronic equipment and manufacturing of motor vehicles. All these sectors contribute significantly to generating considerable emissions from raw material extraction, processing and energy required, use and final destination at the end of its life cycle, becoming trash is classified Municipal Solid Waste (MSW), Waste Electrical and Electronic Equipment (WEEE) and recycling of End-of-Life Vehicles (ELV).

\section{Automotive figures and polymer contribution}

$51,971,328$ units of cars are produced annually worldwide, with an average weight of $1384 \mathrm{~kg}$. The average lifecycle is 14 years [48, 47]. On average, each unit consumes 5.1 liters of gasoline per day and each liter of gasoline combustion emits $2.3 \mathrm{~kg}$ of $\mathrm{CO} 2$ into the atmosphere. In addition, the energy used to produce a gallon of gasoline is $18.3 \mathrm{MJ}$ [48]. Considering that consumed by MJ emitted $0.019 \mathrm{~kg}$ of $\mathrm{CO} 2$ [49], the result is a total power consumption of $59.8 \mathrm{PJ} /$ year, and $1.4 \mathrm{Gt} \mathrm{CO}$ /year.

The cost of manufacturing a car is around 20 to $30 \%$ of the sale price to final consumers and is estimated at 2040€; considering the average price of gasoline globally in the first quarter of 2011 was $1.35 €$ [50] the resulting expenditure was $112 \mathrm{G} € /$ year (112 billion $€$ ).

Of $1.4 \mathrm{Gt} \mathrm{CO} 2 /$ year emitted into the atmosphere, $13 \%$ was due to automobile manufacturing, 50\% to the production of gasoline and $37 \%$ to the combustion of gasoline in the engine. This means that before customers buy and use their car, $50 \%$ of $\mathrm{CO} 2$ has already been produced due to the manufacture of gasoline. Figure 1 summarizes quantity, energy, $\mathrm{CO} 2$ and cost figures for the different types of waste. Figure 2 shows the radar chart type of the relationship between quantity, energy and $\mathrm{CO} 2$ emissions. Vehicle end-of-life profile is indicated by a thick line, and is compared with the other two types of waste. The

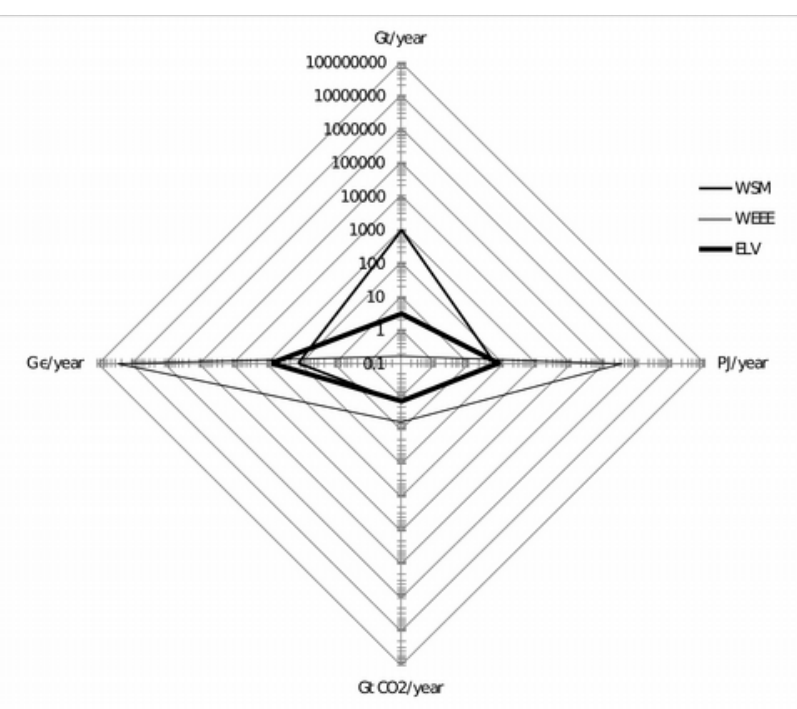

calculation is described below.

Figure 1. Radar graph representing environmental, economic and energy automotive, electronics and municipal waste

Plastics accounted for $6 \%$ of the total ELV power consumption with 13\% (8.1 PJ/year) and 61\% 
$\mathrm{CO} 2$ (0.86 Gt CO2/year). This indicates that more than half of the $\mathrm{CO} 2$ emitted for car manufacture comes from the manufacture of plastics.

The manufacture of electronic devices has a strong impact on consumers, especially in the growth of mobile phones and notebooks (laptops), with an estimated $0.16 \mathrm{Gt}$ of electronics produced and in use annually [51]. According to Liqiu Deng et al. [52] in their study of laptops, the energy required per kilogram of production is $1185 \mathrm{MJ} / \mathrm{kg}, 80 \mathrm{~kg}$ issuing $\mathrm{CO} 2 / \mathrm{kg}$ for manufacturing electronics, and energy consumed already in use is $574 \mathrm{MJ} / \mathrm{kg}$ and

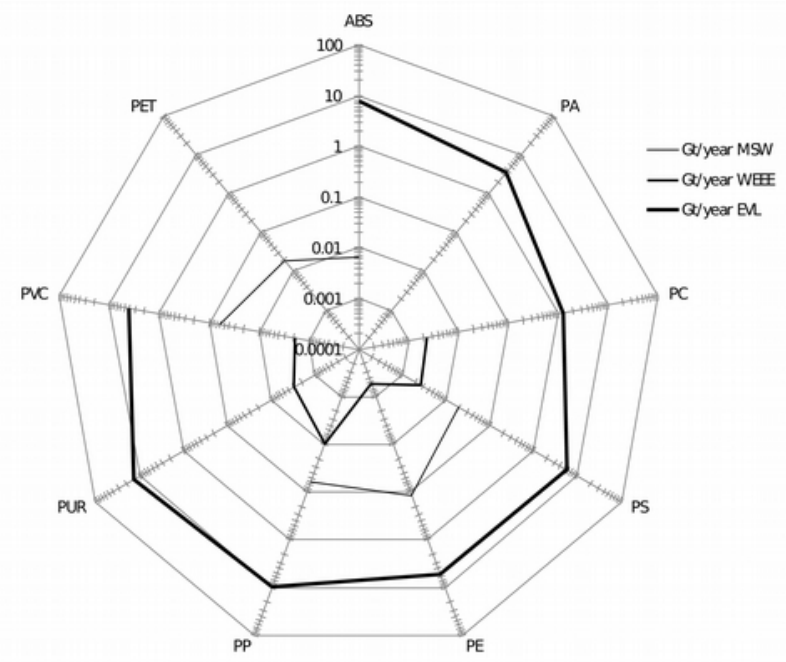

$51 \mathrm{~kg}$ of electronic $\mathrm{CO} 2 / \mathrm{kg}$ with an average life of 3 years.

Figure 2. Radar Graph of plastics only on their environmental $\mathrm{CO} 2$, energy and costs

\section{Electronic devices figures and polymer contribution}

Assuming that the average cost of laptops is $500 €$ / unit (year 2011) with an investment cost per unit of $78 \%$, the energy consumption of a laptop is estimated between 190 to $230 \mathrm{~kW}$, equivalent to $0.2312 € /$ day. From the above estimates of global energy consumption 73,486 $\mathrm{PJ} /$ year, $5.5 \mathrm{Gt}$ $\mathrm{CO} 2 /$ year, and spending of $8875 \mathrm{G} €$ /year (8 billion euro), of which $61 \%$ is invested in the manufacture of electronics and the rest in the payment of electricity by the consumer.

Of the total emissions of $5.5 \mathrm{Gt} \mathrm{CO} 2 /$ year, $60 \%$ occur in manufacturing and $40 \%$ in the use of electronics, considering that the electricity comes from fossil fuels. Figure 1 shows graphically the four aspects of electronic equipment (WEEE).

Plastics represent $36 \%$ of the total weight of WEEE waste, consumes energy but 46\% (33 $893 \mathrm{PJ} /$ year) and 26\% CO2 (1.46 Gt CO2/year), see Figure 2.

Municipal waste figures and polymer
contribution

Municipal solid waste generates approximately 3.1 Gt/year worldwide, resulting in a major urban problem in the world, because it represents a source of infection with about $0.11 \mathrm{Gt} /$ year of food. Conservative estimates by various authors suggest that each human being contributes $454 \mathrm{~kg}$ of municipal waste per year [53-58], energy consumption and $\mathrm{CO} 2$ emissions by treating these products: the solid part needs $47 \mathrm{MJ} / \mathrm{kg}$ and emits $0.9 \mathrm{~kg} \mathrm{CO} 2 / \mathrm{kg}$, the glass $9.4 \mathrm{MJ} / \mathrm{kg}$ and $0.18 \mathrm{~kg}$ $\mathrm{CO} 2 / \mathrm{kg}$, the plastic $68.7 \mathrm{MJ} / \mathrm{kg}$ and $1.3 \mathrm{~kg} \mathrm{CO} 2 / \mathrm{kg}$ and the metal $26 \mathrm{MJ} / \mathrm{kg}$ and $0.49 \mathrm{~kg} \mathrm{CO} 2 / \mathrm{kg}$ [49].

Conservative estimates result in a power consumption of $71.8 \mathrm{PJ} /$ year, $1.3 \mathrm{Gt} \mathrm{CO} 2 /$ year and [51] $702 \mathrm{G} € /$ year (702 billion euros), these are

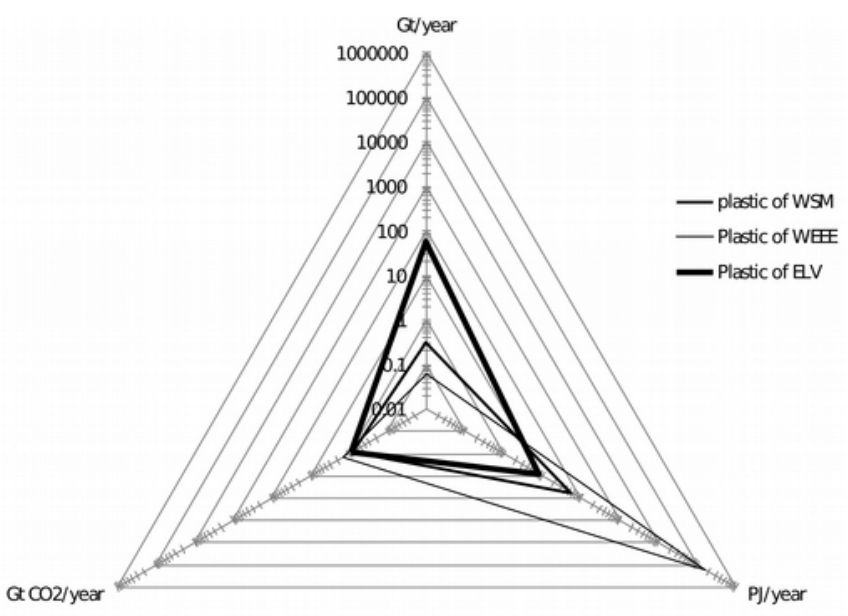

represented in Figure 1.

Figure 3. Radar Graph of the main plastics from MSW, WEEE and ELV in Gt/year

Plastics make up $10 \%$ by weight of total MSW, consumed energy but $76 \%$ (55 PJ/year) and $64 \%$ $\mathrm{CO} 2$ (0.83 Gt CO2/year), this indicates the strong 
ecological impact of plastic MSW, see Figure 2.

Figure 2 shows that total $\mathrm{CO} 2$ emissions from ELV plastics, MSW and WEEE are 3,150,000,000 tons (three billion tons), the amount generated by weight (tons) is very different from $\mathrm{CO} 2$ emissions, as plastics manufactured for WEEE are much lower than that produced by MSW and more than that by EVL, this is shown in the logarithmic radar graph in Figure 3.

Figure 3 shows the tons generated annually and highlights the amount of PUR used in automobiles, followed by PP, PE, PVC and PS values, which are much higher than those produced by MSW and WEEE. MSW is dominated by PE and PVC, followed by PET and ABS. The WEEE is predominantly PP, PS and PC. It can be seen in Figure 3 that the PP, PS and PVC are in MSW, WEEE and ELV, which gives an opportunity to explore different plastics that come from industry and can be used in any of the other sectors.

\section{Analysis of some chemical recycling processes from the standpoint of energy and environment}

As there is not enough real data to propose chemical recycling processes which can give a favorable result in the production of plastic, we present a thermodynamic analysis of energy consumption and $\mathrm{CO} 2$ emissions of this process. The results help identify areas of opportunity for improvement and optimizing the process to reduce effort in more $\mathrm{CO} 2$ emissions by modifying or adapting existing technology. Consequently, recycling processes are themselves consistent with the clean process environment.

\section{Dissolution - reprecipitation process for thermoplastic HDPE}

Figure 4 analyzes the dissolution-reprecipitation process [77]. It involves dissolving a polymer (HDPE) in xylene heated to $150^{\circ} \mathrm{C}$, then cooled to $25^{\circ} \mathrm{C}$. With the addition of a large amount of hexane (compared with xylene) and heated to $80^{\circ} \mathrm{C}$, this initiates the reprecipitation of the polymer that is cooled naturally to $25^{\circ} \mathrm{C}$.

Figure 4 (a) shows a radar graph logarithmic of $1 \mathrm{~kg}$ of plastic obtained. After the process, $0.985 \mathrm{~kg}$ is recovered. The solvents are evaporated directly into the atmosphere. Figure 4 (a) shows the values of energy input (MJ), $\mathrm{CO} 2$ emissions and production costs in euros (investment cost per plant is not considered in this analysis).

Propositions (b) and (c) are evolutions from the initial device and show process improvements.

Figure 4 (b) amending the process in the first phase, cooling the xylene from $150^{\circ} \mathrm{C}$ to $60^{\circ} \mathrm{C}$ (below the temperature of evaporation of hexane) followed by heating to $80^{\circ} \mathrm{C}$. In addition, a distillation tower is installed to induce draft and a condenser to recover the solvents. This leads to a decrease in the energy expended on $\mathrm{CO} 2$ emissions by half and also reduces manufacturing cost.

Figure 4 (c) is another evolution. The heat source comes from a solar heater. The manufacturing cost of this recycling process is drastically lower this recycling process.

\section{Irradiated base process for thermoplastics}

Figure 5 shows a logarithmic radar chart for $1 \mathrm{~kg}$ of plastic. The recycling process is based on irradiation solution technology, and compares two sources. The first, Figure 5 (a) uses cobalt-60 nuclear power and gamma radiations [61], and Figure 5 (b) profile is for electron irradiation [61-65] (electrostatically accelerated by generating enough energy to radiate electrons). This radiation can modify the polymer chains of the plastics, thus modifying their properties. Gamma irradiation (a) is a clean process without generation of $\mathrm{CO} 2$ and a much lower energy investment cost than with electron irradiation (b).

But this analysis does not take into account the nuclear waste impact. Thus quick conclusions should be avoided and a global analysis must be done to effectively compare the different solutions. Again, huge differences appear between different countries, regarding nuclear waste management. 
(a)
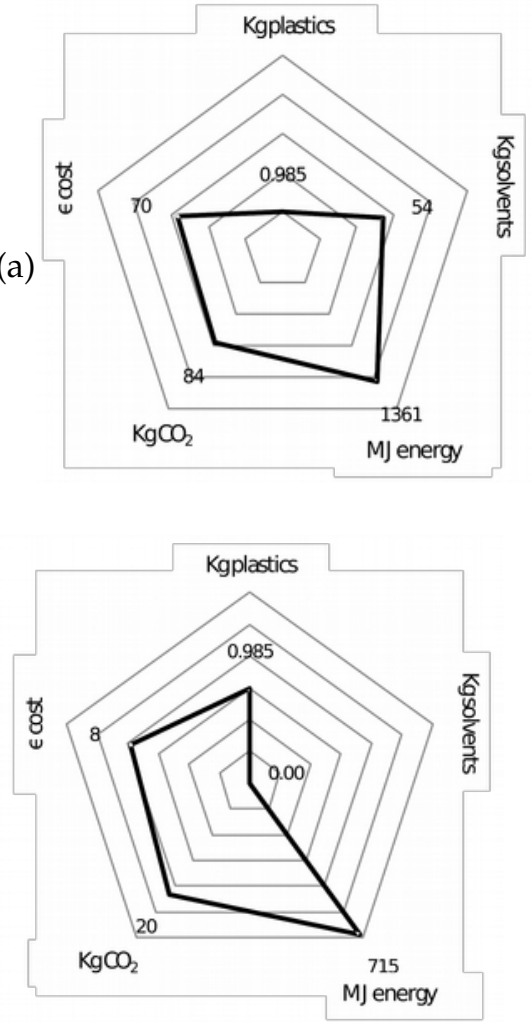

(b)

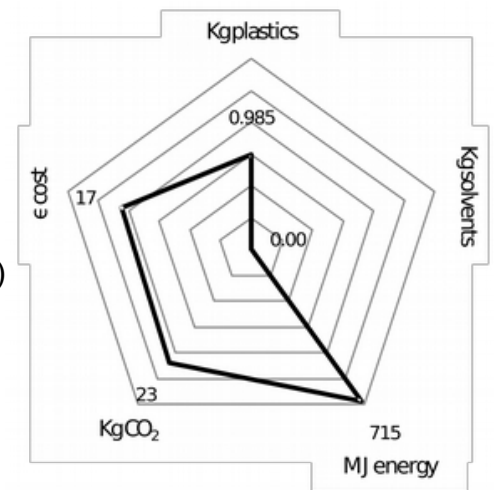

(c)

Figure 4. Logarithm radar graph for improving the dissolution-reprecipitation process.

(a)

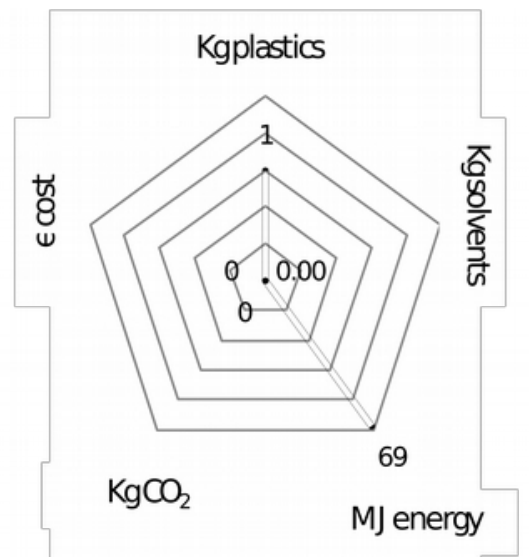

(b)

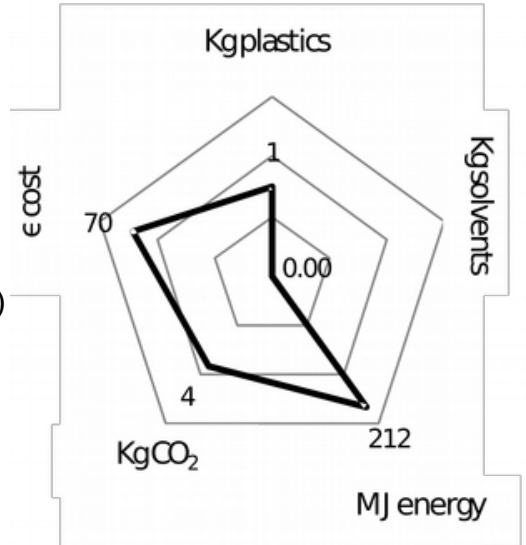

Figure 5. Analysis of recycled (a) gamma irradiation and (b) electron irradiation 


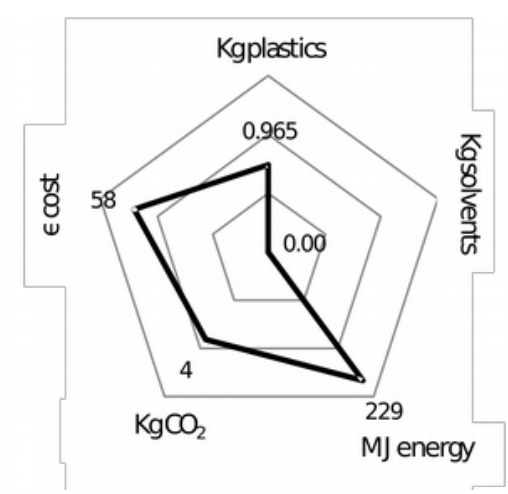

Figure 6. Analysis of fluid-recycling supercritical alcohols

\section{Thermosetting recycling using ethanol}

Figure 6 analyzes the depolymerization of carbonepoxy composites. The thermosetting plastic (epoxy resin $1 \mathrm{~kg}$ ) is extracted with methanol as a solvent. It needs fluid under supercritical behavior [60].

There is a huge need of energy (impact calculation based on nuclear plants) for high pressure and fluid temperatures $\left(275^{\circ} \mathrm{C}\right.$ and $\left.28 \mathrm{MPa}\right)$ in order to separate the epoxy matrix from the carbonreinforced fibers. Alternatives using water solvent are under development and guarantee good mechanical properties of the recycled carbon fibers [59].

\section{PC recycling with solvolysis}

Figure 7 shows PC recycling (1 kg polycarbonate) in a reactor at $250^{\circ} \mathrm{C}$ and $21 \mathrm{MPa}$, using water as a solvent and catalyst $\mathrm{Ca} 2 \mathrm{CO} 3$. The depolymerization process recovers $0.69 \mathrm{~kg}$ of phenol, bisphenol A, and p-isopropenylphenol, which have a profitable value in the market [78, 79]. The energy impact calculation is based on a fuel oil plant.

\section{Conclusions}

The product life cycle is closely linked to the recycling processes and especially to the possibility of remanufacturing the product; this can be achieved by detection of product failures and ongoing feedback on product design. The purpose of either mechanical or chemical

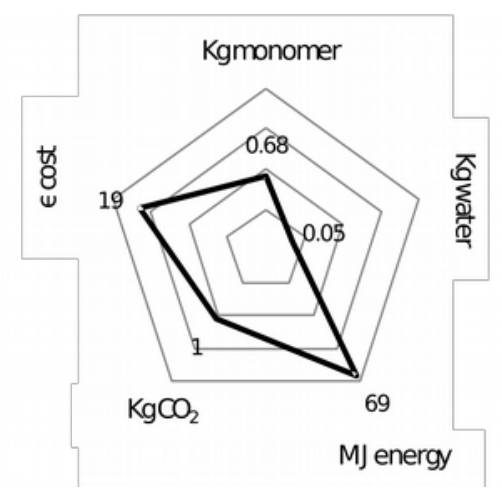

Figure 7. Analysis of hydrolysis recycling

recycling is based on the needs identified in remanufacturing. The quality of the plastic transformation process is subject to continuous improvements being sought, leading to product improvements. Plastic product designers must consider design platforms where they can keep the product with a much longer life cycle and where parts of the product or spare parts may be remanufactured. This would reduce $\mathrm{CO} 2$ emissions dramatically.

Plastics recycling processes should be valued currently from an energy standpoint (MJ), ecological emission (CO2) and profitability (here in $€$ ). This requires support from thermodynamics calculations. We observed that recycling processes can be subjected to this thermodynamic analysis and be capable of being improved by the inclusion of clean technology like solar energy; this leads us to develop clean recycling techniques where the final objective is to reduce $\mathrm{CO} 2$ emissions.

\section{References}

[1] P.S. Monks et al. Atmospheric composition change global and regional air quality, Atmospheric Environment 43 (2009) 5268-5350

[2] Luiz Pingueili Rosa and Roberto Schaeffer, Global warming potentials, Energy Policy, 23, 2 (1995) 149-158.

[3] Michael Johnson, Rufus Edwards, Claudio Alatorre Frenk, Omar Masera, In-field greenhouse gas emissions from cookstoves in rural Mexican households, Atmospheric Environment, 42 (2008) 1206-1222.

[4] R. Wassmann, H. Pathak, Introducing greenhouse gas mitigation as a development objective in rice- 
based agriculture: II. Cost-benefit assessment for different technologies, regions and scales, Agricultural Systems, 94 (2007) 826-840.

[5] CAPE-Last Interglacial Project Members, Last Interglacial Arctic warmth confirms polar amplification of climate change, Quaternary Science Reviews, 25 (2006) 1383-1400.

[6] Alberto V. Reyes*, Duane G. Froese, Britta J.L. Jensen, Permafrost response to last interglacial warming: field evidence from non-glaciated Yukon and Alaska, Quaternary Science Reviews, 29 (2010) 3256-3274.

[7] F. Joos and M. Bruno, Pulse Response Functions are Cost-Efficient Tools to Model the Link Between Carbon Emissions, Atmospheric CO2 and Global Warming, Phys. Chem. Earth, 21, 5-6, (1996) 471476.

[8] Abdolmajid Mahdavi Damghani, Gholamreza Savarypour, Eskandar Zand, Reza Deihimfard, Municipal solid waste management in Tehran: Current practices, opportunities and challenges, Waste Management, 28 (2009) 934-944.

[9] M.T. Carvalho, E. Agante, F. Durão, Recovery of PET from packaging plastics mixtures by wet shaking table, Waste Management, 27 (2007) 17471754.

[10] G. Dodbiba, J. Sadaki, K. Okaya, A. Shibayama, T. Fujita, The use of air tabling and triboelectric separation for separating a mixture of three plastics, Minerals Engineering, 18 (2005) 13501360.

[11] Wu Jiang, Li Jia, Xu Zhen-ming, New two-roll electrostatic separator for recycling of metals and nonmetals from waste printed circuit board, Journal of Hazardous Materials, 161 (2009) 257262.

[12] Per Arild Kjølseth Andresen, Richard Arntzen, Johan Sjøblom, Stability of model emulsions and determination of droplet size distributions in a gravity separator with different inlet characteristics, Colloids and Surfaces, A: Physicochemical and Engineering Aspects, 170 (2000) 33-44.

[13] Sangobtip Pongstabodee, Napatr Kunachitpimo, Somsak Damronglerd, Combination of three-stage sink-float method and selective flotation technique for separation of mixed post-consumer plastic waste, Waste Management, 28 (2008) 475483.

[14] Malcolm Richard Gent, Mario Menendez, Javier Toraño, Diego Isidro, Susana Torno, Cylinder cyclone (LARCODEMS) density media separation of plastic wastes, Waste Management, 29 (2009) 1819-1827.

[15] R.D. Pascoe and Y.Y. Hou, Investigation of the importance of particle shape and surface wettability on the separation of plastics in a Larcodems separator, Minerals Engineering, 12. (1999) 423-431.

[16] Huiting Shent, R.J. Pugh, E. Forssberg, A review of plastics waste recycling and the flotation of plastics, Resources, Conservation and Recycling, 25 (1999) 85-109.

[17] Huiting Shen, R.J. Pugh, E. Forssberg, Floatability, selectivity and flotation separation of plastics by using a surfactant, Colloids and Surfaces A: Physicochemical and Engineering Aspects, 196 (2002) 63-70.

[18] Chul-Hyun Park, Ho-Seok Jeon, Jai-Koo Park, PVC removal from mixed plastics by triboelectrostatic separation, Journal of Hazardous Materials 144 (2007) 470-476.

[19] Mehdi Sadat-Shojai, Gholam-Reza Bakhshandeh, Recycling of PVC wastes, Polymer Degradation and Stability, 96 (2011) 404-415.

[20] Mantaux O., Chibalon L., Lorriot Th., Aurrekoetxea J., Puerto A., Arostegi A., Urrutibeascoa, I., Recycling study of end of life products made of ABS resin, Journal of Materials and Science \& Technology, Vol. 20, Suppl.1 (2004).

[21] C. Le Guern I., P. Conil and R. Houot, Role of calcium ions in the mechanism of action of a lignosulphonate used to modify the wettability of plastics for their separation by flotation, Minerals Engineering, 13 (2000) 53-63.

[22] Huiting Shen, E. Forssberg, R.J. Pugh, Selective flotation separation of plastics by chemical conditioning with methyl cellulose, Resources, Conservation and Recycling, 35 (2002) 229-241.

[23] Huiting Shen, E. Forssberg a, R.J. Pugh, Selective flotation separation of plastics by particle control, Resources, Conservation and Recycling, 33 (2001) 37-50.

[24] Mallampati Srinivasa Reddy, Keisuke Kurose, Tetsuji Okuda, Wataru Nishijima, Mitsumasa Okada, Separation of polyvinyl chloride (PVC) from automobile shredder residue (ASR) by froth flotation with ozonation, Journal of Hazardous Materials, 147 (2007) 1051-1055.

[25] N. Fraunholcz, Separation of waste plastics by froth flotation-a review, part I, Minerals Engineering, 17 (2004) 261-268

[26] Teresa Carvalho, Fernando Durão, Célia Ferreira, Separation of packaging plastics by froth flotation in a continuous pilot plant, Waste Management, 30 (2010) 2209-2215.

[27] Z. Schlett, F. Claici, I. Mihalca, M. Lungu, A new static separator for metallic particles from metalplastic mixtures, using eddy currents, Minerals Engineering, 15 (2002) 111-113. 
[28] Masayuki Araya, Toshifumi Yuji, Takayuki Watanabe, Junzou Kashihara, Yoshitake Sumida, Application to cleaning of waste plastic surfaces using atmospheric non-thermal plasma jets, Thin Solid Films, 515 (2007) 4301-4307.

[29] Paul Walker, Tim Kelley, Comparison of a static gravity screen-roll press combination separator to a PAM-assisted gravity belt thickener system for swine waste slurry solids separation, Bioresource Technology, 96 (2005) 571-576.

[30] Mikio Yoshida, Shingo Nakatsukas, Masaaki Nanba, Kuniaki Gotoh, Tatsuya Zushi, Yasuo Kubo, Jun Oshitani, Decrease of $\mathrm{Cl}$ contents in waste plastics using a gas-solid fluidized bed separator, Advanced Powder Technology, 21 (2010) 69-74.

[31] Z. Schlett, M. Lungu, Eddy-current separator with inclined magnetic disc, Minerals Engineering, 15 (2002) 365-367.

[32] Amar Tilmatine, Karim Medles, Salah-Eddine Bendimera, Fodil Boukholda, Lucien Dascalescu, Electrostatic separators of particles: Application to plastic/metal, metal/metal and plastic/plastic mixtures, Waste Management, 29 (2009) 228-232.

[33] C.P. Chu, D.J. Lee, J.H. Tay, Gravitational sedimentation of flocculated waste activated sludge, Water Research, 37 (2003) 155-163.

[34] Nusruth Mohabuth, Philip Hall, Nicholas Miles, Investigating the use of vertical vibration to recover metal from electrical and electronic waste, Minerals Engineering, 20 (2007) 926-932.

[35] Chenlong Duan, XuefengWen, Changsheng Shi, Yuemin Zhao, BaofengWen, Yaqun He, Recovery of metals from waste printed circuit boards by a mechanical method using a water medium, Journal of Hazardous Materials, 166 (2009) 478482

[36] Thongchai Takoungsakdakun, Sangobtip Pongstabodee, Separation of mixed post-consumer PET-POM-PVC plastic waste using selective flotation, Separation and Purification Technology, 54 (2007) 248-252.

[37] Harvey Alter, The recovery of plastics from waste with reference to froth flotation, Resources, Conservation and Recycling, 43 (2005) 119-132.

[38] Y. Tachwali, Y. Al-Assaf, A.R. Al-Ali, Automatic multistage classification system for plastic bottles recycling, Resources, Conservation and Recycling, 52 (2007) 266-285.

[39] Feliks Bezati, Daniel Froelich, Valérie Massardier, Elisabeth Maris, Addition of X-ray fluorescent tracers into polymers, new technology for automatic sorting of plastics: Proposal for selecting some relevant tracers, Resources, Conservation and Recycling, July (2011).
[40] Edward H. Jones, Colin C. Smith, Non-equilibrium partitioning tracer transport in porous media: 2-D physical modelling and imaging using a partitioning fluorescent dye, Water Research, 39, (2005) 5099-5111.

[41] F. Bezati, D. Froelich, V. Massardier, E. Maris, Addition of tracers into the polypropylene in view of automatic sorting of plastic wastes using X-ray fluorescence spectrometry, Waste Management, 30, (2010) 591-596.

[42] J. Bastek, N.A. Stolwijk, Th. K.-J. Köster, L. van Wüllen, Systematics of salt precipitation in complexes of polyethylene oxide and alkali metal iodides, Electrochimica Acta, 55 (2010) 1289-1297.

[43] Eusebio Ventura Jr., Mark A. Nearing, L. Darrell Norton, Developing a magnetic tracer to study soil erosion, CATENA, 43, (2001) 277-291.

[44] Vincenzo Gente, Floriana La Marca, Federica Lucci, Paolo Massacci, Electrical separation of plastics coming from special waste, Waste Management, 23, (2003), 951-958.

[45] Vincenzo Gente, Floriana La Marca, Federica Lucci, Paolo Massacci, Eleonora Pani, Cryo-comminution of plastic waste, Waste Management, 24 (2004) 663-672.

[46] Sujit Das, T. Randall Curlee, Colleen G. Rizy, Susan M. Schexnayder, Automobile recycling in the United States: Energy impacts and waste, Resources, Conservation and Recycling, 14 (1995) 265-284.

[47] http://www.worldometers.info/cars/

[48] www.revistamene.com/nuevo/index2.php? option=com_content\&do_pdf=1\&id=1787.

[49] A.L. Leão, Ing Hwie Tan, Potential of municipal solid waste (MSW) as a source of energy in São Paulo: its impact on $\mathrm{CO} 2$ balance, Biomass and Bioenergy, 14 (1998) 83-89.

[50] petrolnews.net/noticia.php? ID=7d13938ee3aebee856f9e9badfa349c8\&r=15896.

[51] Innocent Chidi Nnorom, Oladele Osibanjo, Electronic waste (e-waste): Material flows and management practices in Nigeria, Waste Management, 28 (2008), 1472-1479.

[52] Liqiu Deng, Callie W. Babbitt, Eric D. Williams, Economic-balance hybrid LCA extended with uncertainty analysis: case study of a laptop computer, Journal of Cleaner Production, 19 (2011) 1198-1206.

[53] S. S. Chung, C. S. Poon, Evaluating waste management alternatives by the multiple criteria approach, Resources, Conservation and Recycling, 17 (1996) 189-210.

[54] M. E. Kaseva, S. E. Mbuligwe, G. Kassenga, Recycling inorganic domestic solid wastes: results from a pilot study in Dar es Salaam City, 
Tanzania, Resources, Conservation and Recycling, 35 (2002) 243-257.

[55] Yung Yau, Domestic waste recycling, collective action and economic incentive: The case in Hong Kong, Waste Management, 30 (2010) 2440-2447

[56] Foo Tuan Seik, Recycling of domestic waste: Early experiences in Singapore, Habitat International, 21 (1997) 277-289.

[57] P. M. Subramanian, Plastics recycling and waste management in the US, Resources, Conservation and Recycling, 28 (2000) 253-263.

[58] Confédération suisse, Quelle est la quantité de CO2 émise par la consommation d'un kilowattheure (kWh) d'électricité en Suisse?, Office fédéral de 1 'environnement OFEV, 2008.

[59] Mantaux O., Aymonier C., Antal M., Recycling of carbon fibre reinforced composite materials with super- critical water dissolution, 16th National Composite Days Proceeding, Toulouse, juin (2009).

[60] Aymonier C., Loppinet-Serani A., Reverón H., Garrabos Y., Cansell F., , Review of supercritical fluids in inorganic materials science, The Journal of Supercritical Fluids, 38 (2006) 242-251.

[61] E.Adem, M. Avalos-Borja, D. Carrillo, M, Vazquez, E. Sanchez,M.P. Carreon and G.Burillo, Crosslinking of recycled polyethylene by gamma and electron beam irradiation, Radiut. Physc. Chem., 52 (1998) 171176.

[62] Y.H. Gad, M.M. Magid, H.H. El-Nahas, Effect of ionizing irradiation on the thermal blend of waste low density polyethylene/ethylene vinyl acetate/bitumen for some industrial applications, Journal of Industrial and Engineering Chemistry, 16 (2010) 1019-1024.

[63] Fumio Y oshii, Gamal Meligiz Takashi Sasaki, Keizo Makuuchi, Abdelgawad M. Rabie and Seiichi Nishimoto, Effect of irradiation on the degradability of polypropylene in the natural environment, Polymer Degradation and Stability 49 ( 1995) 315-321.

[64] Ajit Singh, Irradiation of polymer blends containing a polyolefin, Radiation Physics and Chemistry, 60 (2001) 453-459.

[65] Guillermina Burillo, Roger L. Clough, Tibor Czvikovszky, Olgun Guven, Alain Le Moel, Weiwei Liu, Ajit Singh, Jingtian Yang, Traian Zaharescu, Polymer recycling: potential application of radiation technology, Radiation Physics and Chemistry, 64 (2002) 41-51.

[66] Khait, K., Riddick, E.G., Torkelson, J.M., 2002. http://www.Sperecycling.org/GPEC/ GPEC2002/papers/0137.PDF, Recovery of PostConsumer Plastic Waste Via Solid State Mechanochemistry.
[67] Khait, K., Torkelson, J.M.,Solid-state shear pulverization of plastics: a green recycling process. Polymer-Plastics Technology and Engineering 38 (1999) 445-457.

[68] Furgiuele N, Lebovitz AH, Khait K, Torkelson JM. Polym Eng Sci 2000;40:1447e57.

[69] Lebovitz AH, Klementina Khait and John M. Torkelson, Efficient mixing of polymer blends of extreme viscosity ratio: Elimination of phase inversion via solid-state shear pulverization, Polymer Engineering \& Science, Volume 40, (2000) 1447-1457.

[70] Lebovitz AH. Ph.D. thesis, Northwestern University; 2003.

[71] Cavalieri, F., Padella, F., 2002. Development of composite materials by mechanochemical treatment of post-consumer plastic waste. Waste Management 22 (8), 913-916.

[72] Cavalieri, F., Padella, F., Bourbonneux, S., Romanelli C., 2000. Mechanochemical recycling of mixed plastic waste. In: First International Conference on Polymer Modification, Degradation, Stabilization, Palermo, Italy, 3-7 September.

[73] Padella, F., Magini, A., Incocciati, E., 1998. Patent No. RM98000372.

[74] Andrew H Lebovitz, Klementina Khait, John M Torkelson, Sub-micron dispersed-phase particle size in polymer blends: overcoming the Taylor limit via solid-state shear pulverization, Original Research Article, Polymer, 44 (2003) 199-206.

[75] E. Bilgili, H. Arastoopour, B. Bernstein, Pulverization of rubber granulates using the solidstate shear extrusion SSSE/ process: Part I. Process concepts and characteristics, Powder Technology, 115 (2001) 265-276.

[76] D. Schocke, H. Arastoopour, B. Bernstein, Pulverization of rubber under high compression and shear, Powder Technol., 102 (1999) 207-214.

[77] D.S. Achilias, C. Roupakias, P. Megalokonomos, A.A. Lappas, E.V. Antonakou, Chemical recycling of plastic wastes made from polyethylene (LDPE and HDPE) and polypropylene (PP), Journal of Hazardous Materials, 149 (2007) 536-542.

[78] Hideyuki Tagaya, Kazuya Katoh, Jun-ichi Kadokawa, Koji Chiba, Decomposition of polycarbonate in subcritical and supercritical water, Polymer Degradation and Stability, 64 (1999) 289-292.

[79] Yoshiki Sato, Yasuhiko Kondo, Koji Tsujita, Noboru Kawai, Degradation behaviour and recovery of bisphenol-A from epoxy resin and polycarbonate resin by liquid-phase chemical recycling, Polymer Degradation and Stability, 89 (2005) 317-326. 